\title{
Factors Related to Medication Adherence of Cognitively Impaired Patients in Community Pharmacies
}

\author{
Yoko Nanaumi ${ }^{1}$, Mitsuko Onda ${ }^{2 *}$, Yusuke Mukai ${ }^{2}$, Rie Tanaka $^{2}$, Kenichi Tubota ${ }^{2}$, \\ Syunya Matoba ${ }^{2}$, Yuka Tanaka ${ }^{2}$, Yukio Arakawa ${ }^{2}$ \\ ${ }^{1}$ Advance Pharma Research Office, Nara, Japan; ${ }^{2}$ Clinical Laboratory of Practical Pharmacy, Osaka University of Pharmaceutical \\ Sciences, Osaka, Japan. \\ Email: ${ }^{*}$ onda@gly.oups.ac.jp
}

Received March 2 $2^{\text {nd }}, 2012$; revised April 23 ${ }^{\text {rd }}, 2012$; accepted May $6^{\text {th }}, 2012$

\begin{abstract}
Objective: The objective of the study was to identify factors related to donepezil medication adherence ("adherence") of cognitively impaired patients in community pharmacies. Methods: One hundred and twenty community pharmacies in 28 regions in Japan were randomly selected. Questionnaires were mailed to these pharmacies. The pharmacists answered based on the medication profiles ("YAKUREKI") of the patients given donepezil at their pharmacies. The survey items were "adherence", "who is the key person" and the key person's understanding and awareness of donepazil and its symptoms. The $\chi^{2}$ test and decision tree modeling analysis were performed to examine factors affecting adherence. A 5\% level of statistical significance was used in the $\chi^{2}$ test. Results: Questionnaires with data on 479 patients were returned. The most common level of adherence was "take as instructed" $(81.2 \%)$, followed by "forget once or twice a week" $(10.2 \%)$. The $\chi^{2}$ test revealed that adherence was good if "key person" was professional caretaker $(\mathrm{P}=$ 0.004). Also, adherence was better if key person understood medication about dosage, $\mathrm{P}<0.001$; effect, $\mathrm{P}=0.002$; and general side effects, $\mathrm{P}<0.001$. According to decision tree analysis, the key person had the strongest relationship with adherence. Conclusions: It was confirmed that the key person's understanding of the medication and symptoms of cognitive impairment are related to adherence. In particular, it was suggested that there is a strong relationship between the key person and adherence and that factors related to adherence differ according to who the key person is. It is essential in the treatment of cognitive impairment to accurately identify the "key person", in order to provide better pharmaceutical care in community pharmacies.
\end{abstract}

Keywords: Japan; Pharmacist; Community Pharmacy; Medication; Adherence; Cognitive Impairment

\section{Introduction}

It is estimated that over $25 \%$ of the Japanese population will be 65 years of age or older by 2015. The Japanese Ministry of Health, Labor and Welfare estimated that the number of people 75 years of age and older would be about 14 million in 2009 [1]. About 120,000 out of these people will have cognitive impairment [2].

We know that it is essential for medication to be taken continually in the treatment of cognitive impairment and that maintaining treatment adherence is the key to improving the quality of treatment and the quality of life [3]. There is an abundance of research on factors related to medication adherence ("adherence") worldwide. It has been suggested that such factors include age [4,5], sex [6], economic status [5], disease severity [5], degree of cognitive dysfunction [7], complications [5,8], drug regimen prescribed [6,9], cooperation from family [10],

${ }^{*}$ Corresponding author. physician-patient relationship [7,11], patient satisfaction [12], and generic substitution [13]. Inadequate awareness of the necessity to follow the treatment regimen has been identified as a reason for the patient's decision to discontinue treatment of their own accord [4].

Research on adherence in patients with cognitive impairment includes studies on factors such as persistence (refill adherence) and duration for multiple cholinesterase inhibitors [14-16]. These studies suggest that the type of drug and ease of use affect continuation or discontinuation of treatment [18], and that the sex, age, and degree of economic burden from medication costs affect adherence to treatment regimens for cognitive impairment [17]. A study compared treatment adherence in outpatients for multiple medications for cognitive impairment (multiple cholinesterase inhibitors) $[18,19]$. Belle SH et al. inspected the influence of medication for cognitive enhancement on family care-givers, and suggested that there is substantial geographic variability and effects de- 
pending on the physician's education [20], Sevilla C et al. compared satisfaction of the care-givers on cognitive impairment medications prescribed for the patient [21].

There are no studies on adherence of cognitively impaired patients, but several studies examined the adherence on medication for some diagnoses in Japan. Hayashi et al. identified irregularity of meals as a factor related to adherence in a survey of inpatients with ischemic heart disease, by checking whether or not patients forgot to take their medication on a 2-grade yes/no scale [22]. Ishida et al. demonstrated the beneficial effect of one dose packaging in an evaluation of adherence to an oral antidiabetic drug regime based on whether diabetics could take their medication per physician's instructions (evaluated on a three-grade scale of "I am taking medication," "sometimes forget," and "often forget") [23]. Yamaoka et al. evaluated adherence to a $\alpha$-glucosidase inhibitor on a four-grade scale ("take all as instructed," "usually take," "sometimes take," and "don't take") and demonstrated that adherence was lower than with other oral antidiabetic agents [24]. Tatemichi et al. demonstrated that adherence improved according to the instructtions given by physician in an evaluation of long-term adherence in male Japanese workers using a four-grade scale (always took the drug according to the prescription (complete), occasionally forgot to take the drug (good), frequently forgot to take the drug (poor), always forgot to take the drug (very poor)) [25]. Evaluating adherence on a four-grade scale for forgetting to take medication or having left-over medication ("happens a lot," "sometimes happens," "doesn't happen very often," "almost never happens"), Kamei et al. identified occupation and having diabetes as factors affecting adherence [26].

Most of the previous research in Japan has been performed at specific medical institutions or in specific communities; none has been performed on patients with cognitive impairment over a wide area in a community pharmacy setting. The purpose of this study is therefore to identify factors related to adherence of cognitively impaired patient.

There are several assessment methods for adherence, mainly consisting of pill counting methods such as the MEMS (Medication-Event-Monitoring System) [27], and self-administered rating scales such as the Morisky Scale, which assesses adherence by scoring the frequency with which patients forget to take medication or discontinue their medication [28]. Hiratsuka et al. studied the validity of the 4-grade Drug Compliance Scale (DCS), consisting of 4 items, by using it in combination with pill counting; however, their study suggested that only 2 of the items were valid [29]. Nevertheless, pill counting devices such as the MEMS are not widely available in Japan, nor are Japanese translations of assessment tools such as the Morisky Scale widely accepted. Thus, while several methods for assessing adherence are available in Japan, a unified assessment method has not been established.

We therefore performed a pilot study of assessment scales among pharmacists and selected the most universally used assessment scale for use in the present study. The assessment tool selected is a patient profiling system that is used by pharmacies throughout Japan for collecting data on adherence and related factors across multiple geographic regions.

This profiling system in Japan is called the "YAKUREKI". Regulations concerning the "YAKUREKI" mandate community pharmacists to "record data for monitoring and counseling patients". Information to be recorded is specified by the Japanese Health Insurance Law (Table 1). Since Japanese pharmacies do not have technicians or other certified support staff who dispense drugs and provide medicine work, pharmacists are the only ones who deal with patients. As a result, several different pharmacists often work on the same cases. The purpose of the "YAKUREKI" profile is for pharmacists to share information on patients in order to maintain the quality of pharmacists' counseling.

Table 1. Items to be included in "YAKUREKI" under the Rule of Pharmacies Dispensing Fee Schedule.

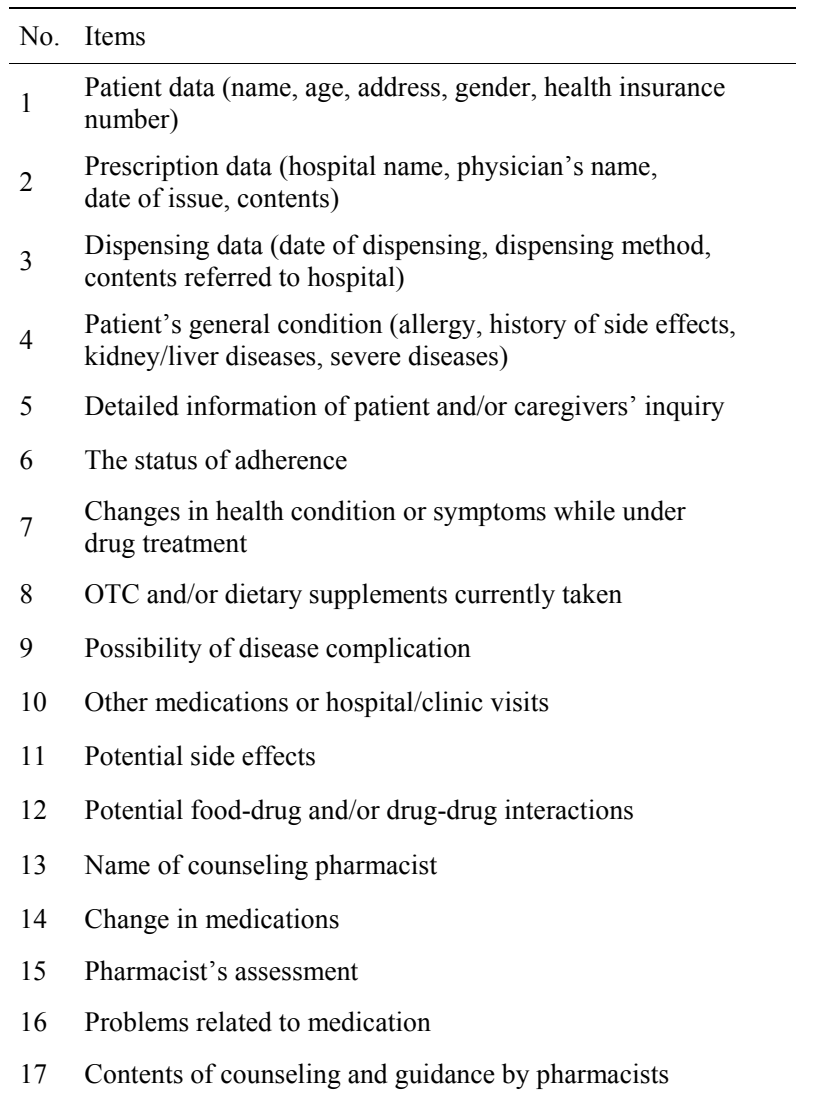

YAKUREKI Fee targets $=1-13$

Pharmaceutical counseling fee targets $=14-17$ 
Keeping medication records using "YAKUREKI" has been required as standard skill for community pharmacists by Health Insurance Law in Japan.

So, the training for handling "YAKUREKI" is one of the core-requirements in undergraduate program.

A schematic depiction of the research protocol appears in Figure 1 below.

In general, the target patients with cognitive impairment are identified by checking the disease name on their prescriptions. But in Japan, no prescriptions carry disease names, so the only way to select patients with cognitive impairment is by checking the medication contents. In Japan, donepezil $\mathrm{HCl}$ is used in symptomatic treatment that controls the progression of cognitive disorders including dementia of the Alzheimer's type (AD), mild cognitive impairment (MCI), and dementia with Lewy bodies (DLB). This acetylcholinesterase inhibitor was the only drug approved in Japan for the treatment of cognitive impairment when this study was conducted at the end of June 2010

\section{Subjects and Methods}

\subsection{Subjects and Survey Methods}

One hundred and twenty community pharmacies in 28 of the 47 regions throughout Japan were randomly selected using the Domestic Sales Data of Donepezil for the survey. These establishments were selected from among pharmacies that had dispensed donepezil using random number generated by computer.

This number of pharmacies was calculated based on the assumption reached by our pilot study that there would be data from 100 patients (50 in the "good" ad- herence group and 50 in the "poor" adherence group), with a response rate of $50 \%$, and that data from 2 patients could be obtained per pharmacy. Pharmacies were provided with a general explanation of the survey and pharmacies with no patients taking donepezil were excluded.

The questionnaire consisting of 20 items in 10 domains (Table 2) was mailed to the supervising pharmacists at the participating pharmacies. Pharmacists who had counseled patients on the use of donepezil were requested to record and evaluate information in these patients' profiling system ("Yakureki") in the questionnaire. The completed questionnaire forms were returned by mail. The questionnaire was based on a review of previous studies, cognitive impairment treatment guidelines, and information gleaned from meetings with academics and pharmacists. The questionnaire was then reworked into its present state after a pilot study using 5 pharmacists. So that care-giver and familial recognition influence it for cognitive impairment medical treatment [30], We should conduct an investigation into recognition of care-giver in an item of this study, We have to describe "key person" because we set this research based on recording of interview at counter in community pharmacy as investigation subject, therefore the degree of caregiver is various by degree of cognitive impairment, it is difficult to make judge who is care-giver at counter in community pharmacy because of various person coming to receive medicine.

\subsection{Statistical Methods}

The $\chi^{2}$ test was performed using the level of adherence and other survey items. Adherence was categorized as

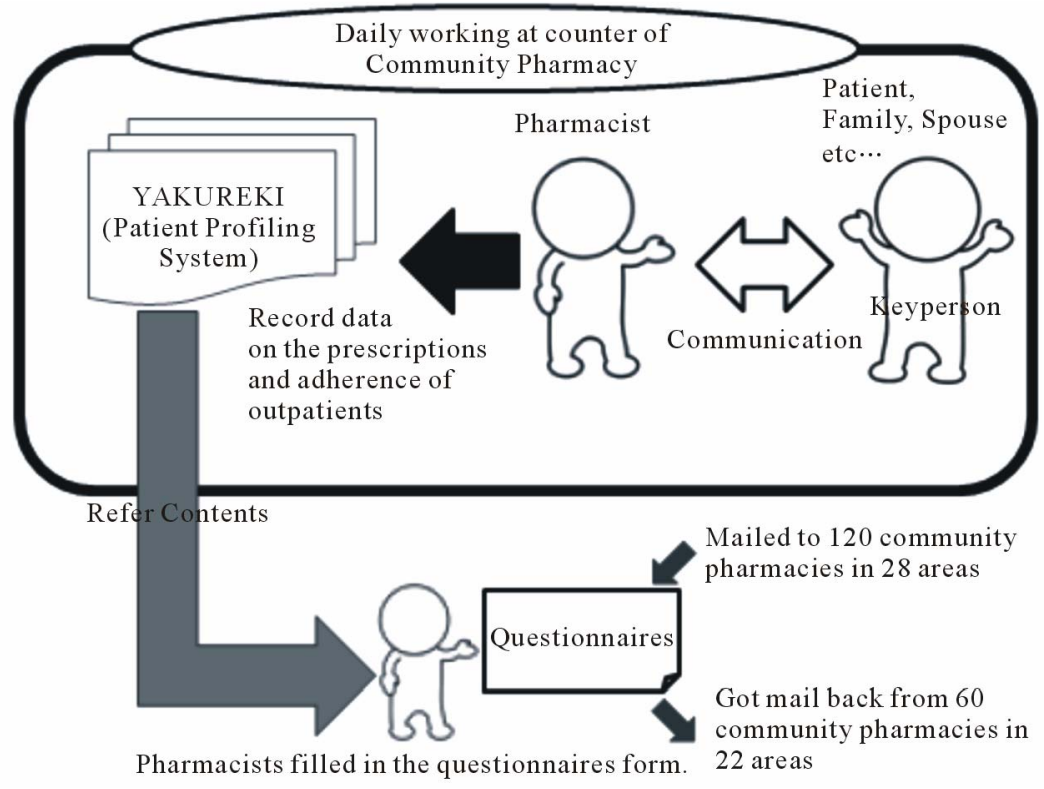

Figure 1. Process of study. 
Table 2. Questionnaire items (20 items, 10 domains).

1-a). Sex

1) Patient profile

2) Regimen prescribed 1-b). Age

1-c). Medical institution visited

2-a). Donepezil strength

2-b). Dosage form

2-c). Dosage

2-d). Supply dispensed per prescription

2-e). How dispensed

2-f). Concomitant drugs

3) Physician's consultation status

4) Donepezil adherence

scored on a four-grade scale

5) "Key person" who has the central role in overseeing the donepezil adherence

6-a). Understanding of donepezil administration and dosage

scored on a four-grade scale

6) Key person's understanding of donepezil

7) Key person's understanding of cognitive impairment 6-b). Understanding of effect

6-c). Understanding of general side effects

7-a). Understanding of the characteristic symptoms of cognitive impairment

7-b). Understanding of the treating physician's treatment plan

8) Key person's awareness of own cognitive impairment

9) Key person's awareness of therapeutic effect

10) Key person's attitude toward treatment (positive/negative)

scored on a four-grade scale

scored on a four-grade scale

scored on a four-grade scale scored on a four-grade scale scored on a four-grade scale scored on a four-grade scale scored on a four-grade scale "good" ("take all as instructed") or "poor" ("forget once or twice a week," "only take once or twice a week," "never take"). "Information unavailable". "unknown," and "no response" were excluded as missing data. The following factors were each divided into 2 groups: age ( $\leq 74$ years and $\geq 75$ years), supply dispensed per prescription (in days) ( $\leq 29$ days and $\geq 30$ days), and number of concomitant drugs ( $\leq 4$ and $\geq 5$ ). "Key person" was divided into 4 groups: patient, spouse, family member other than spouse, and professional caretaker (Table 3). The decision tree analysis was performed, using adherence level as the target variable and items suggested by the $\chi^{2}$ test to be related to adherence as independent variables.

Of the various methods of decision tree analysis, we used CRT (classification and regression trees). In the CRT analysis, a branch splits in two at the cutoff point showing the largest change in impurity found by Gini measurement among a combination of cutoff points for all independent variables used ("Impurity" refers to the extent to which responses are concentrated in a single target category in a node). This process then repeats itself. The "good" adherence group was selected as the target category. The minimum number of cases per group before running the analysis (the parent nodes) was set at 100 and the minimum per group after running the analysis (the child nodes) was set at 50. The analysis was considered completed when a minimum of 100 cases in the parent node and 50 cases in the child node was reached. The Windows versions of SPSS (18.0J) and SPSS Decision Tree software packages were used in the analysis. A level of significance of less than $5 \%$ was used.

\section{Results}

\subsection{Questionnaire Return Rate}

Four-hundred-and-seventy-nine patient data responses were collected from 60 community pharmacies in 22 regions throughout Japan (Figure 2).

\subsection{Results}

The results of each of the questionnaire items are shown in Table 4 and Table 5.

More than half of the patients visited a "clinic or physician's office" for treatment. $79.1 \%$ of the patients were prescribed a $5 \mathrm{mg}$ tablet once daily, with treatment 
Table 3. Items and groups used in the $x^{2}$ test.

\begin{tabular}{|c|c|c|}
\hline Questionnaire item & Response & Group \\
\hline \multirow{4}{*}{ Medical facilities patient visited } & University hospitals & \\
\hline & Public hospitals & Hospital \\
\hline & Private hospitals & \\
\hline & Clinics or physician's offices & physician's office \\
\hline \multirow{2}{*}{ Physcian's consultation status } & Patient sees physician & Patient sees physician \\
\hline & Patient only gets medication w/o seeing physician & Patient only gets medication w/o seeing physician \\
\hline \multirow{3}{*}{ Dispensing methods of Donepezil } & Alone in a heat-sealed packet & Donepezil alone \\
\hline & One-dose packages alone & \multirow[b]{2}{*}{ One dose packaging } \\
\hline & One-dose packages with other drugs & \\
\hline \multirow{4}{*}{$\begin{array}{l}\text { Key person's understanding } \\
\text { (dosage, effect, general side effect) }\end{array}$} & Understands well & \multirow{2}{*}{ Understands } \\
\hline & Mostly understands & \\
\hline & Does not understand very well & \multirow[b]{2}{*}{ Does notunderstand } \\
\hline & Does not understand at all & \\
\hline \multirow{4}{*}{$\begin{array}{l}\text { Key person's awareness of } \\
\text { own cognitive impairment }\end{array}$} & Well aware & \multirow{2}{*}{ Aware } \\
\hline & Generally aware & \\
\hline & Not very well aware & \multirow{2}{*}{ Not aware } \\
\hline & Completely unaware & \\
\hline \multirow{4}{*}{$\begin{array}{l}\text { Key person's awareness } \\
\text { of therapeutic effect }\end{array}$} & Has a thorough awareness & \multirow{2}{*}{ Has awareness } \\
\hline & Has a general awareness & \\
\hline & Does not have a very good awareness & \multirow[b]{2}{*}{ Does not have awareness } \\
\hline & Has no awareness & \\
\hline \multirow{4}{*}{$\begin{array}{l}\text { Key person's attitude toward } \\
\text { cognitive impairment treatment }\end{array}$} & Positive & \multirow{2}{*}{ Positive } \\
\hline & Somewhat positive & \\
\hline & Somewhat negative & \multirow{2}{*}{ Negative } \\
\hline & Negative & \\
\hline
\end{tabular}

regimen stating "to be taken after breakfast". There was an average of 3.1 concomitant medications.

$77 \%$ of the patients were accompanied by someone when visiting their physicians. $10 \%$ visited their physiccians for treatment alone. This information was not clear for $12 \%$ of the patients.

$81.2 \%$ of the patients were found to be adherent. A family member other than the spouse was the most common "key person", followed by the spouse, the patient himself/herself, and a professional caretaker, in that order.

There were common tendencies in the key person's understanding of donepezil and cognitive impairment, as well as the awareness of own cognitive impairment. The most common degree of understanding was "mostly un- derstand", followed by "well", "not very well", and "not at all", in that order.

As for the therapeutic effect, the most common response was "do not have a very good understanding" followed by "have no understanding".

Concerning the attitude toward treatment, there was a common tendency on the understanding and awareness on the part of the key person: "unknown" was the highest at $35.9 \%$.

\subsection{Factors Affecting Adherence to the Donepezil Regimen}

The $\chi^{2}$ analysis of the key person's relationship to adherence to the donepezil regimen revealed that a higher per- 


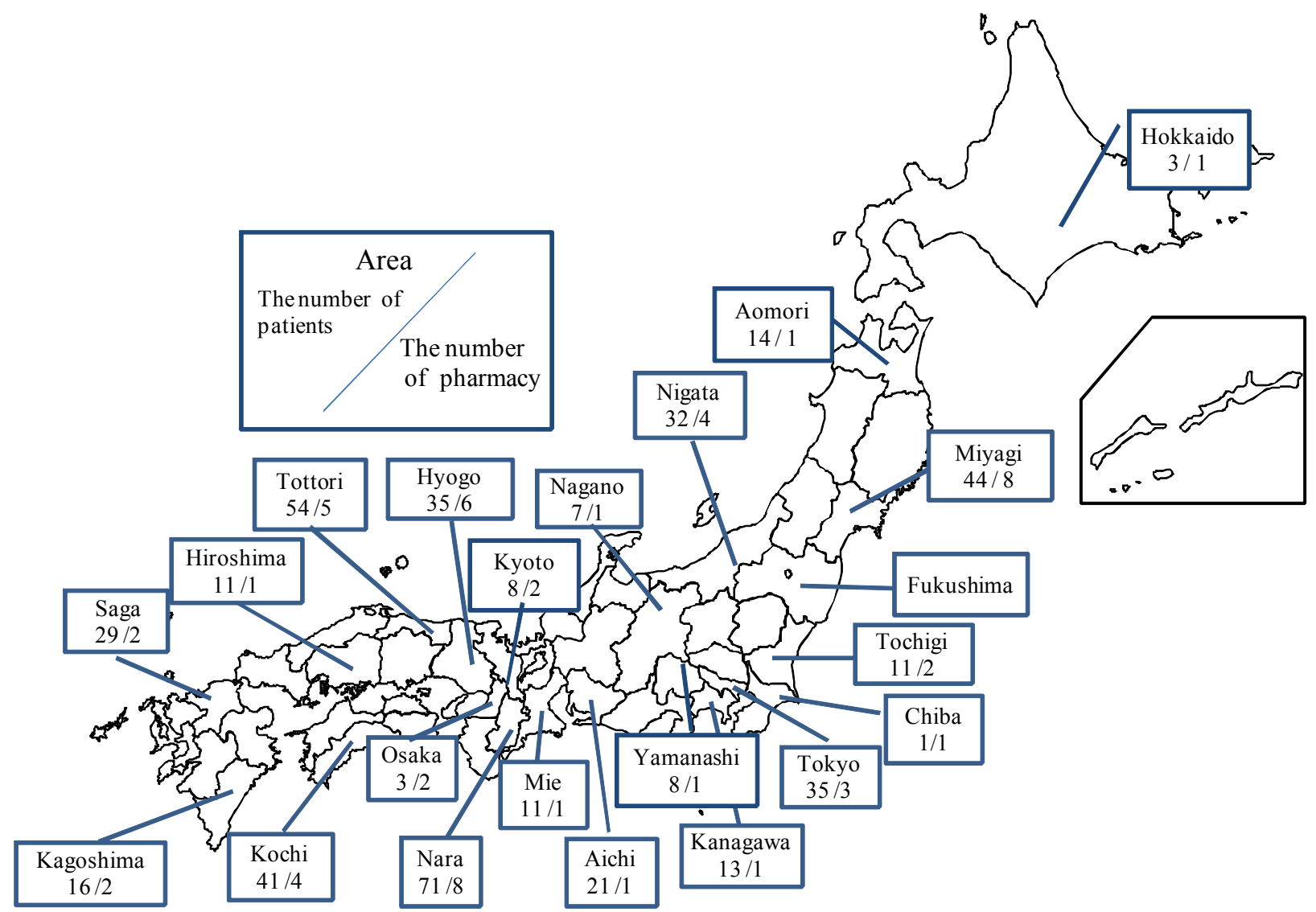

Figure 2. Distribution of responses.

centage of patients with "a professional caretaker" had "good" adherence than patients with the other three key person types, whereas a lower percentage of patients with "a family member other than the spouse" as the key person showed "good" adherence than patients in the three other key person types $(\mathrm{P}=0.004)$ (Table 6). The $\chi^{2}$ test was also used to compare patients with themselves ("patients") as the key person with those with "a professional caretaker" as the key person, revealing a higher rate of "good" adherence when "a professional caretaker" was the key person $(\mathrm{P}=0.034)$.

The $\chi^{2}$ analysis of the relationship between adherence and the key person's understanding of donepezil revealed that a higher percentage of "good" adherence was seen when the key person "understands," compared to when the key person "does not understand" all donepezilrelated items (administration and dosage, $\mathrm{P}<0.001$; effects, $\mathrm{P}=0.002$; general side effects, $\mathrm{P}<0.001$ ).

The results for the $\chi^{2}$ analysis of other factors related to donepezil adherence are discussed below. The key person's understanding of cognitive impairment: There were significant differences for understanding of both "characteristic symptoms" and "physician's treatment plan." A higher percentage of "good" adherence was seen when the key person "understands" than when the key person "does not understand" $(\mathrm{P}<0.001)$. The key person's awareness of patient's illness: There was a higher percentage of "good" adherence when the keyperson was "aware" than when he/she was "not aware" of patient's illness $(\mathrm{P}=0.001)$. Keyperson's awareness of therapeutic effect: There was a higher percentage of "good" adherence when the key person "is aware" than when the key person "is not aware" of the therapeutic effect $(\mathrm{P}=0.001)$. Key person's attitude toward cognitive impairment treatment (positive/negative): There was a higher percentage of "good" adherence when the key person was "positive" than when the key person was "negative" about treatment $(\mathrm{P}<0.001)$. The factors sex, age, medical institution visited, regimen prescribed, and whether patient personally sees physician to get prescription did not show a relationship with adherence.

\subsection{Building the Decision Tree Model}

There were 418 subjects in the analysis, after excluding patients for whom the "information was unavailable" or there was "no response." Figure 3 shows the results of the decision tree analysis conducted at the first parent node (node 0 ). A total of 6 child nodes (nodes 1 to 6 ) were obtained in this analysis. Four of these (nodes 3 to 6 ) 
Table 4. Results-1.

\begin{tabular}{|c|c|c|c|}
\hline \multirow{2}{*}{\multicolumn{2}{|c|}{ 1-a). Sex }} & Male & $34.0 \%$ \\
\hline & & Female & $66.0 \%$ \\
\hline \multirow{4}{*}{ 1) Patient profile } & 1-b). Age & Av. 81.0 yrs (S.D.7.1) & \\
\hline & & Clinic or physician's office & $55.4 \%$ \\
\hline & & Private hospital & $21.5 \%$ \\
\hline & 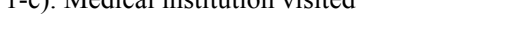 & Public hospital & $18.0 \%$ \\
\hline \multirow{19}{*}{ 2) Regimen prescribed } & & University hospital & $5.1 \%$ \\
\hline & & Tab $3 \mathrm{mg}$ & $3.1 \%$ \\
\hline & & Tab $5 \mathrm{mg}$ & $24.2 \%$ \\
\hline & & Tab $10 \mathrm{mg}$ & $0.2 \%$ \\
\hline & 2-a). Donepezil strength \& 2-b). Dosage form & OD tab $3 \mathrm{mg}$ & $9.0 \%$ \\
\hline & & OD tab $5 \mathrm{mg}$ & $54.9 \%$ \\
\hline & & OD tab $10 \mathrm{mg}$ & $8.4 \%$ \\
\hline & & Fine granule & $0.2 \%$ \\
\hline & & Before Breakfast & $0.9 \%$ \\
\hline & & After Breakfast & $88.9 \%$ \\
\hline & & After Lunch & $0.6 \%$ \\
\hline & $2-6) .00$ sage & After Dinner & $7.9 \%$ \\
\hline & & Before Bed & $0.9 \%$ \\
\hline & & Other & $0.9 \%$ \\
\hline & 2-d). Supply dispensed per prescription & Av. 33.5 days (S.D., 20.5) & \\
\hline & & Alone in a blister package & $56.3 \%$ \\
\hline & 2-e). How dispensed & One-dose packages with other drugs & $39.1 \%$ \\
\hline & & One-dose packages with donepezil alone (without other drugs) & $4.7 \%$ \\
\hline & 2-f). Concomitant drugs & Av. 3.1 medicines (S.D., 2.9) & \\
\hline \multirow{3}{*}{\multicolumn{2}{|c|}{ 3) Physician consultation status }} & Patient himself/herself sees physician & $77.5 \%$ \\
\hline & & Someone besides the patient sees the physician & $10.0 \%$ \\
\hline & & Unknown & $12.5 \%$ \\
\hline \multirow{5}{*}{\multicolumn{2}{|c|}{ 4) Donepezil adherence }} & Take all as instructed (4) & $81.2 \%$ \\
\hline & & Forget once or twice a week (3) & $10.2 \%$ \\
\hline & & Only take once or twice a week (2) & $0.9 \%$ \\
\hline & & Never take (1) & $0.2 \%$ \\
\hline & & Information unavailable (0) & $7.5 \%$ \\
\hline \multirow{4}{*}{\multicolumn{2}{|c|}{$\begin{array}{l}\text { 5) "Key person" who has the central role in overseeing } \\
\text { the donepezil adherence }\end{array}$}} & A family member other than spouse such as a daughter & $38.6 \%$ \\
\hline & & Spouse & $22.6 \%$ \\
\hline & & Patient & $22.3 \%$ \\
\hline & & Professional caretaker & $16.5 \%$ \\
\hline
\end{tabular}


Table 5. Results-2.

6) Key person's understanding of donepezil 6-b). Understanding of effect

6-c). Understanding of general side effect 6-a). Understanding of donepezil administration and dosage

7-a). Understanding of the characteristic symptoms of cognitive impairment

7) Key person's understanding of cognitive impairment

8) Key person's awareness of own cognitive impairment

10) Key person's attitude toward treatment (positive/negative) 7-b). Understanding of the treating Physician's treatment plan

\begin{tabular}{|c|c|}
\hline Understands well (4) & $31.30 \%$ \\
\hline Mostly understands (3) & $40.30 \%$ \\
\hline Does not understand very well (2) & $7.50 \%$ \\
\hline Does not understand at all (1) & $1.50 \%$ \\
\hline Unknown (0) & $19.40 \%$ \\
\hline Understands well (4) & $22.30 \%$ \\
\hline Mostly understands (3) & $46.80 \%$ \\
\hline Does not understand very well (2) & $9.20 \%$ \\
\hline Does not understand at all (1) & $1.50 \%$ \\
\hline Unknown (0) & $20.30 \%$ \\
\hline Understands well (4) & $13.40 \%$ \\
\hline Mostly understands (3) & $39.50 \%$ \\
\hline Does not understand very well (2) & $17.70 \%$ \\
\hline Does not understand at all (1) & $2.90 \%$ \\
\hline Unknown (0) & $26.50 \%$ \\
\hline Understands well (4) & $16.3 \%$ \\
\hline Mostly understands (3) & $42.8 \%$ \\
\hline Does not understand very well (2) & $13.2 \%$ \\
\hline Does not understand at all (1) & $1.5 \%$ \\
\hline Unknown (0) & $26.3 \%$ \\
\hline Understands well (4) & $19.2 \%$ \\
\hline Mostly understands (3) & $37.2 \%$ \\
\hline Does not understand very well (2) & $12.7 \%$ \\
\hline Does not understand at all (1) & $1.3 \%$ \\
\hline Unknown (0) & $29.6 \%$ \\
\hline Well aware (4) & $26.5 \%$ \\
\hline Mostly aware (3) & $37.8 \%$ \\
\hline Not very aware (2) & $10.2 \%$ \\
\hline Completely unaware (1) & $1.7 \%$ \\
\hline Unknown (0) & $23.8 \%$ \\
\hline Has a thorough awareness (4) & $7.1 \%$ \\
\hline Has a general awareness (3) & $20.7 \%$ \\
\hline Does not have a very good awareness (2) & $26.5 \%$ \\
\hline Has no awareness (1) & $2.9 \%$ \\
\hline Unknown (0) & $42.8 \%$ \\
\hline Positive (4) & $15.4 \%$ \\
\hline Somewhat positive (3) & $39.5 \%$ \\
\hline Somewhat negative (2) & $7.9 \%$ \\
\hline Negative (1) & $1.3 \%$ \\
\hline Unknown (0) & $35.9 \%$ \\
\hline
\end{tabular}

9) Key person's awareness of therapeutic effect 
Table 6. Factors related to adherence.

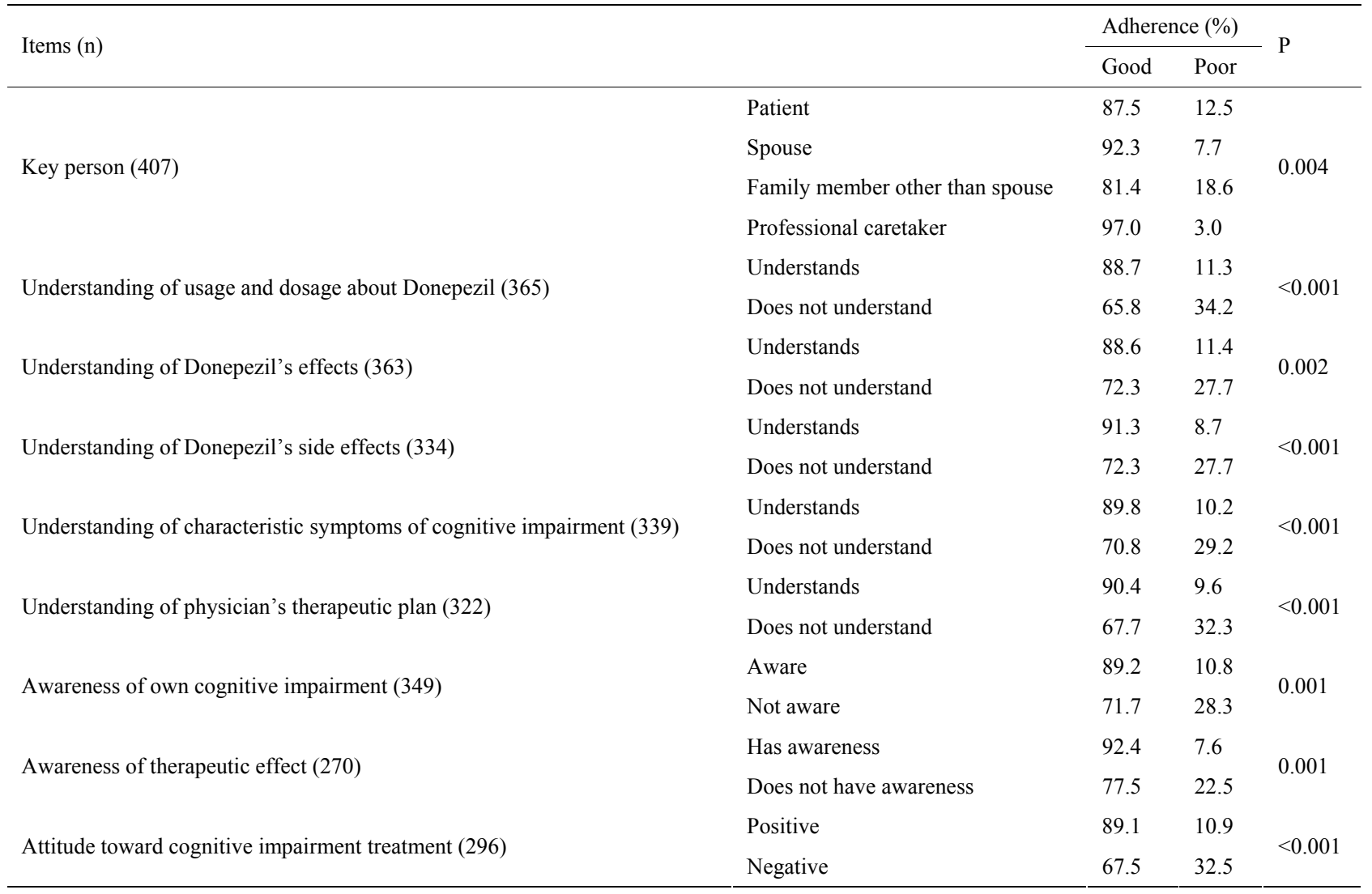

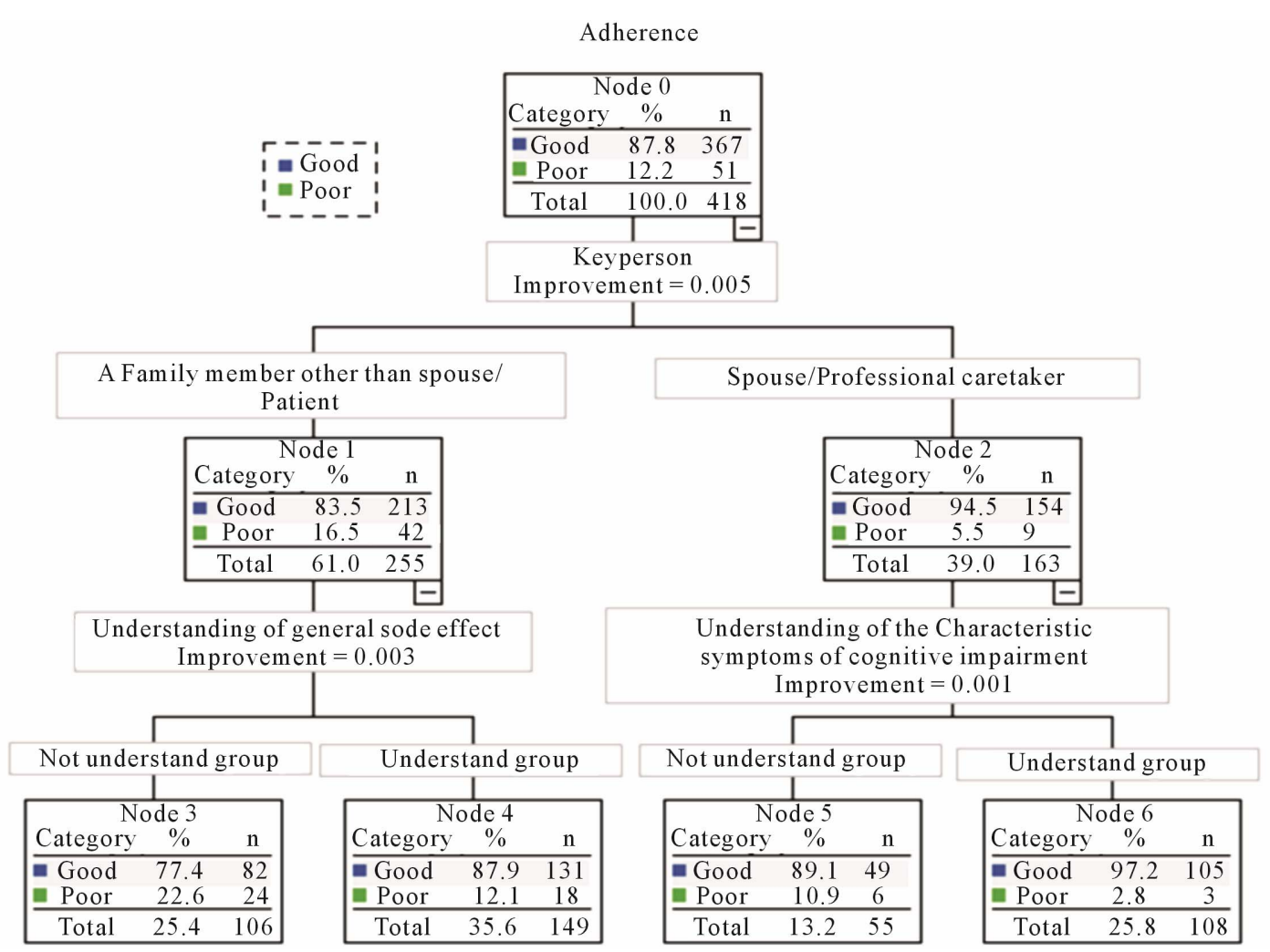

Figure 3. The result of decision tree analysis. 
were terminal nodes (where splitting stopped). The deepest splitting in the decision tree model was to the 2 nd level.

"Key person" was selected as the factor that would be split at node 0 . On the process of the decision tree modeling, the key person was split on the group having "the patient" or "a family member other than the spouse" as the key person (node 1) and the group having "the spouse" or "a professional caretaker" as the key person (node 2), and there was a higher percentage of "good" adherence in node 2 than node 1 . Nodes 1 and 2 were also split at the next level. "The key person's understanding of donepezil's side effects" was selected as the factor on which node 1 would be split. There was a higher rate of "good" adherence in the group that gave the response of "4. Understands well" and " 3 . Mostly understands" (node 4) for "key person's understanding of donepezil's side effects" than in the group that responded "2. Does not understand very well" to " 0 . Unknown" (node 3). Node 2 was split on the factor "the key person's understanding of the characteristic symptoms of cognitive impairment". There was a higher rate of "good" adherence in the group that gave the response of "4. Understands well" or "3. Mostly understands" (node 6) for "the key person's understanding of the characteristic symptoms of cognitive impairment" than in the group that responded " 2 . Does not understand very well" or " 0 . Unknown" (node 5).

Decision trees are generally "pruned" to limit the number of levels so that the results will not be overly complex. However, since the analysis stopped after generating only 2 levels, we did not do any pruning and used the results here as is.

\section{Discussion}

In our study, $81.2 \%$ of the patient data showed "take all as instructed". The results indicated that general adherence to donepezil treatment regimens was good in outpatients with cognitive impairment. This trend is consistent with previous studies $[18,19]$. The $\chi^{2}$ test results also suggested that all types of key persons contributed to adherence, that not only a professional caretaker but also a family member involved contributed to the adherence to donepezile, and that it was possible that adherence could improve with education by pharmacist to the key person.

Our result suggested that the relationship of the key person with adherence is such that adherence is comparatively low when the key person is the patient himself/herself or a family member other than the spouse, and that adherence is good when the key person is "a professional caretaker". This may be because it is highly likely that a patient with a professional caretaker as the key person lives in a care facility and adherence is maintained because the facility staff manages the patient's medication.

This issue is correspondent with the issue written by Kemuyama, which said care workers in care facilities of cognitively impared patients are required to stay compliant by recognizing the symptoms [31].

Furthermore, our results implied that maintaining adherence has a linkage with improving knowledge about the medication (knowledge of donepezil administration and dosage, effects, and general side effects) and with improving the key person's understanding of the symptoms of cognitive impairment and the physician's treatment plan. The relationship with adherence of the key person's awareness of his own cognitive impairment may be such that if the key person is aware that he has cognitive impairment, the significance of the drug treatment regimen will become clear and adherence will be maintained. It was also confirmed that the key person's awareness of the effectiveness of the therapy and attitude toward the treatment (positive/negative) are related to maintaining adherence. Donepezil does not promise to improve symptoms markedly; rather, the objective of the therapy is to "maintain the status quo" by slowing down the progression of symptoms. Given the nature of donepezil therapy for cognitive impairment, the present results suggested that the ability to increase the key person's understanding of the significance of taking donepezil or his or her awareness of its effectiveness holds the key to improved attitude toward the treatment (positive/ negative) and, in turn, maintaining adherence.

The results of the decision tree modeling showed that the key person has the strongest relationship with adherence. On the process of the decision tree analysis, key person was split on the group having "the patient" or "a family member other than the spouse" as the key person (node 1) and the group having "the spouse" or "a professsional care taker" as the key person (node 2). Node 1 was then split on "the key person's understanding of donepezil's side effects," and node 2 was split on "the key person's understanding of the characteristic symptoms of cognitive impairment." This suggests that the first step in maintaining and improving adherence is to know who the "key person" is.

The extent of the key person's involvement in care giving may be the reason why the factors related to adherence differed according to who the key person is. Since "the spouse" or "a professional caretaker " at node 2 is frequently in a position to directly support the patient's activities of daily life, there was a tendency for adherence to be higher when the key person's understanding of the patient's symptoms was good. Conversely, with "a family member other than the spouse or patient" at node 1, adherence tended to be higher when 
there was a good understanding of side effects because 1) there is a tendency to deny the presence of cognitive impairment and 2) a good understanding of the side effects eliminates resistance to and anxiety about taking the medication.

Jane R. et al. said it is important that a pharmacist educates the care-giver of the cognitively impaired patient [32], and this research suggested the possibility that "education to have you understand the symptoms of cognitive impairment" was effective.

The results also suggested that "to educate about symptom of cognitive impairment" is more effective for persons who are directly involved in the care such as the spouse or caretakers.

In addition, Sen-Roy states that a pharmacist should tell the patient and his or her family that the drug used in the treatment of cognitive impairment is for the purpose of maintaining the status quo [29], but our study suggested that it is important that the pharmacist informs about the "side effects and cognitive impairment symptoms". Furthermore, it was suggested that points of reporting were different by key person.

A study about classification of care-givers of cognitive impairment patients, report on a male spouse [34] and an unpleasant female spouse [35], but our study suggests the possibility that education for a family except the spouse influenced adherence to medication.

Jane R. mentions the education that pharmacist provides to the care-giver should be done based on the observation of the behavioral disorder of the cognitive impairment patients living in the local area, because pharmacists are able to contact them on a regular basis [28].

We believe that we were able to clearly state "what kind of education is effective for what kind of caregiver" by this study.

Mort and Tasler wrote that pharmacists must educate caregivers of cognitive impairment patients [28], and our present study also suggested that educating caregivers on the symptoms of cognitive impairment is potentially effective. Sen-Roy wrote that the patient and his or her family should be told that medications for cognitive impairment simply maintain the status quo [29]. However, our results confirmed that it is important to provide information about the side effects of cognitive impairment medications and the symptoms of the disease, as well as the "effects" of the medication. In addition, our results suggested that the information to be provided to key persons differs according to who the key person is.

In the present study, we performed a statistical analysis of data based on the information that pharmacists record in the patients' profiling system called "YAKUREKI", but there were many responses of "Unknown" for certain items on the survey, reflecting the fact that a sufficient amount of information is not being obtained and/or the pharmacist may have transcribing errors. This is because it is difficult for the pharmacist to directly confirm the patient's condition and the pharmacist can only hear indirectly from caregivers, family members, and the like, since there are many cases in which the person who visits the pharmacy is not the patient himself/ herself, given the nature of cognitive impairment. Consequently, pharmacists must make a greater effort to collect information from the people who go to pharmacies to receive medicines and from other healthcare professionals, and to record more information in the profiling system.

\section{Limitations of the Study}

The objective of the present study was to identify factors related to treatment adherence in outpatients with cognitive impairment by examining the regimens prescribed and treatment adherence at community pharmacies in Japan. However, we became aware of 2 limitations to the study due to its special circumstances.

The first limitation is that it is difficult to identify patients with cognitive impairment because pharmacists at Japanese community pharmacies cannot view the medical records kept by physicians and diagnoses are not written on prescriptions. We therefore considered patients prescribed donepezil to be "patients with cognitive impairment" because the acetylcholinesterase inhibitor was the only drug approved for cognitive impairment in Japan at the time of the survey. As a result, one cannot rule out the possibility that patients with cognitive impairment not taking donepezil were excluded from the study.

The second limitation concerns the method of assessing adherence. The authors developed their own measures of adherence since a standardized assessment tool does not exist in Japan. In the present study, we did not question patients directly about adherence, but rather selected a protocol under which pharmacists performed an objective assessment using data in the profiling system. Therefore, we concluded that an evaluation using pill counts and multiple choices would not be valid as an adherence assessment scale for the present study, and we adopted an assessment scale in which "information unavailable" was added to a 4-grade scale for frequency of forgetting to take medication per week. The pharmacists who participated in the pilot study said that this assessment scale afforded easy communication with the key person, enabling them to make an assessment reflecting the actual situation. It was therefore concluded that the present assessment method would not present major problems in the interpretation of the results.

\section{Conclusion}

It was confirmed that the key person's understanding of 
the medication and symptoms of cognitive impairment are related to adherence in outpatients with cognitive impairment. In particular, it was suggested that there is a strong relationship between the key person and adherence and that factors related to adherence differ according to who the key person is. It is therefore essential in the treatment of cognitive impairment to accurately identify the key person, collect suitable information on the patient, provide the counseling desired, and provide instructions on taking the medication.

\section{REFERENCES}

[1] Japan Ministry of Health, Labor and Welfare, "Survey of Medical Care Activities in Public Health Insurance 2007," 2007.

[2] Seed Planning, Inc., "Japanese Patient Population Analysis and Epidemiological Survey," Japan, 2007

[3] N. Bassil and G. T. Grossberg, "Novel Regimens and Delivery Systems in the Pharmacological Treatment of Alzheimer's Disease," CNS Drugs, Vol. 23, No. 4, 2009, pp. 293-307. doi:10.2165/00023210-200923040-00003

[4] K. Tanaka, T. Obara, M. Kobayashi, T. Shinki, T. Shibamiya, M. Nishimura, K. Gonokami, A. Hara, T. Ohkubo, S. Oide and Y. Imai, "Medication Compliance and Intentional Discontinuation of Taking Medication among Outpatients," Research on Drug Interactions, Vol. 32, No. 3, 2009, pp. 131-137.

[5] R. G. Barr, S. C. Somers, F. E. Speizer and C. A. Camango Jr., "Patient Factors and Medication Guideline Adherence among Older Women with Asthma," Archives of Internal Medicine, Vol. 162, 2002, pp. 1761-1768. doi:10.1001/archinte.162.15.1761

[6] B. S. Bloom, "Daily Regimen and Compliance with Treatment," BMJ (Clinical Research Edition), Vol. 323, No. 7324, 2001, p. 647.

[7] J. Okuno, H. Yanagi and S. Tomura, "Is Cognitive Impairment a Risk Factor for Compliance among Japanese Elderly in the Community?" European Journal of Clinical Pharmacology, Vol. 57, No. 8, 2001, pp. 589-594. doi:10.1007/s002280100347

[8] M. Monane, R. L. Bohn, J. H. Gurwitz, R. J. Glynn, R. Levin and J. Avorn, "The Effects of Initial Drug Choice and Comorbidity on Antihypertensive Therapy Compliance: Results from a Population Based Study in the Elderly," American Journal of Hypertension, Vol. 10, No. 7, 1997, pp. 697-704. doi:10.1016/S0895-7061(97)00056-3

[9] K. A. Payne and S. Esmonde-White, "Observational Studies of Antihypertensive Medication Use and Compliance: Is Drug Choice a Factor in Treatment Adherence?" Current Hypertension Reports, Vol. 2, 2000, pp. 515-524. doi:10.1007/s11906-996-0035-6

[10] F. Martin-Rayes and M. Rodriguez-Moran, "Family Support of Treatment Compliance in Essential Arterial Hypertension," Salud Pública de México, Vol. 43, No. 4, 2001, pp. 336-339.

[11] N. Kerse, S. Buetow, A. G. Mainous III, G. Young, G.
Coster and B. Arroll, "Physician-Patient Relationship and Medication Compliance: A Primary Care Investigation," Annals of Family Medicine, Vol. 2, No. 5, 2004, pp. 455461. doi:10.1370/afm.139

[12] L. E. Harris, F. C. Luft, D. W. Rudy and W. M. Tierney, "Correlates of Health Care Satisfaction in Inner-City Patients with Hypertension and Chronic Renal Insufficiency," Social Science \& Medicine, Vol. 41, No. 12, 1995, pp. 1639-1645. doi:10.1016/0277-9536(95)00073-G

[13] B. L. Van Wijk, O. H. Klungel, E. R. Heerdink and A. de Boer, "Generic Substitution of Antihypertensive Drugs: Does It Affect Adherence?" Annals of Pharmacotherapy, Vol. 40, No. 1, 2006, pp. 15-20. doi:10.1345/aph.1G163

[14] S. Gadzhanova, L. Roughead and J. Mackson, "Anticholinesterase Duration in the Australian Veteran Population," Australian and New Zealand Journal of Psychiatry, Vo. 44, No. 5, 2010, pp. 469-474.

[15] N. Hermann, C. Binder, W. Daiziel, S. Smyth and F. Camacho, "Persistence with Cholinesterase Inhibitor Therapy for Dementia: An Observational Administrative Health Database Study," Drugs Aging, Vol. 26, No. 5, 2009, pp. 403-407.

[16] J. A. Mauskopf, C. Paramore, W. C. Lee and E. H. Snyder, "Drug Persistency Patterns for Patients Treated with Rivastigmine or Donepezil in Usual Care Settings," Journal of Managed Care Pharmacy, Vol. 11, No. 3, 2005, pp. 231-239.

[17] B. Borah, P. Sacco and V. Zarotsky, "Predictors of Adherence among Alzheimer's Disease Patients Receiving Oral Therapy," Current Medical Research and Opinion, Vol. 26, No. 6, 2010, pp. 1957-1965. doi: $10.1185 / 03007995.2010 .493788$

[18] L. Blais, Z. Kettani, S. Perreaulf, J. C. Leroux, A. Forget and M. J. Kergoat, "Adherence to Cholinesterase Inhibitors in Patients with Alzheimer's Disease," Journal of the American Geriatrics Society, Vol. 57, No. 2, 2009, pp. 366-368. doi:10.1111/j.1532-5415.2009.02075.x

[19] O. Schwalbe, C. Scheerans, I. Freiberg, A. SchmidtPokrzywniak and A. Stang, "Compliance Assessment of Ambulatory Alzheimer Patients to Aid Therapeutic Decisions by Healthcare Professionals," BMC Health Services Research, 2010, pp. 10-232.

[20] S. H. Belle, S. Zhang, S. J. Czaja, R. Burns and R. Schulz, "Use of Cognitive Enhancement Medication in Persons with Alzheimer Disease Who Have a Family Caregiver: Results from the Resources for Enhancing Alzheimer's Caregiver Health (REACH) Project," American Journal of Geriatric Psychiatry, Vol. 12, No. 3, 2004, pp. 250257. doi:10.1176/appi.ajgp.12.3.250

[21] C. Sevilla, P. E. Jiménez Caballero, V. Alfonso and M. González-Adalid, "Current treatments of Alzheimer Disease: Are Main Caregivers Satisfied with the Drug tReatments Received by Their Patients?" Dementia and Geriatric Cognitive Disorders, Vol. 28, No. 3, 2009, pp. 196-205. doi: $10.1159 / 000236015$

[22] M. Hayashi, E. Takeo, M. Okada, K. Gotou, K. Iritani and T. Suzuki, "Questionnaire Survey on Taking Medi- 
cine, and a Study of the Improved Compliance in Ischemic Heart Disease Patients," Journal of Japanese Society of Hospital Pharmacists, Vol. 41, No. 11, 2004, pp. 1403-1406.

[23] K. Ishida, "Compliance for Oral Antidiabetic Agents and its Improvement by One dose Package," Journal of Japanese Society of Hospital Pharmacists, Vol. 26, No. 6, 2000, pp. 674-678. doi:10.5649/jiphes1975.26.674

[24] K. Yamaoka, S. Fukuzumi, K. Yosizumi, E. Iguchi, M. Sasaki, Y. Nakajima and T. Yamauchi, "An Evaluation of Compliance for $\alpha$-Glucosidase Inhibitor," Journal of Japanese Society of Hospital Pharmacists, Vol. 25, No. 2, 1999, pp. 204-211. doi:10.5649/jiphcs1975.25.204

[25] M. Tatemichi, T. Hamaguchi, M. Hashira, T. Hayashi, M. Ito, A. Nakatani, H. Hiro, K. Mori, Y. Ookubo, T. Ezaki, H. Sugimori and K. Yoshida, "Acceptability and LongTerm Compliance with Drug Treatment for Hypercholesterolemia in Japanese Male Workers: I. Acceptability of Drug Treatment," Journal of Occupational Health, Vol. 44, 2002, pp. 166-175. doi:10.1539/joh.44.166

[26] M. Kamei and M. Onda, "Effects of Deregulation on Prescription Term for Outpatients' Drug Therapy," The Journal of Japan Society for Health Care Management, Vol. 4, No. 3, 2003, pp. 377-383.

[27] R. B. Haynes, D. W. Taylor, D. L. Sackett, E. S. Gibson, C. D. Bernholz and J. Mukherjee, "Can Simple Clinical Measurement Detect Patient Noncompliance?" Hypertension, Vol. 2, 1980, pp. 757-764. doi:10.1161/01.HYP.2.6.757

[28] M. Paul, J. Cara, H. Elizabeth, H. Jiang, M. Donald, S. Larry, Webber and K. W. Marie, "Defining the Minimal
Detectable Change in Scores on the Eight Item Morisky Medication Adhererance Scale," The Annals of Pharmacotherapy, Vol. 45, 2011, pp. 569-575. doi:10.1345/aph.1P677

[29] S. Hiratuka, H. Kumano, J. Katayama, Y. Kishikawa, T. Hishinuma, Y. Yamauchi and M. Mizugaki, "Drug Compliance Scale I-Development of Drug Compliance Scale," Yakugaku Zasshi, Vol. 120, No. 2, 2000, pp. 224-229.

[30] V. Cotrell, K. Wild and T. Bader, "Medication Management and Adherence among Cognitively Impaired Older Adults," Journal of Gerontological Social Work, Vol. 47, No. 3-4, 2006, pp. 31-46. doi:10.1300/J083v47n03 03

[31] S. Kemuyama, "Recognition of Depression State in Dementia by Care Workers and Nurses and Problems Encountered," Health Sciences Bulletin Akita University, Vol. 17, No. 2, 2009, pp. 59-69.

[32] J. R. Mort and M. K. Tasler, "Managing DementiaRelated Behavior in the Community," Journal of the American Pharmaceutical Association, Vol. NS36, No. 4, 1996.

[33] S. Sen-Roy, “Alzheimer's Disease: A Review," Pharmacy Practice (Mississauga), Vol. 18, No. 4, 2002, p. C1.

[34] Y. Kobayashi, "The Recognition of Caregiving and the Factors Affecting It of Elderly Husbands Caring tor Demented Wives," Journal of Japan Academy of Gerontological Nursing, Vol. 9, No. 2, 2005, pp. 64-76.

[35] G. G. Ocana, R. G. Robles, D. S. Vinuesa and F. L. De Castro, "Family Repercussions Due to Alzheimer Disease," Rev Enferm, Vol. 30, No. 3, 2007, pp. 59-64. 